\title{
Monseñor Romero y los mártires Selección de textos
}

\section{Miguel Cavada, Centro de Reflexión Teológica, San Salvador.}

En artículos anteriores' hemos analizado diversos aspectos de la vida, obra y teología de Monseñor Romero. En éste queremos analizar su pensamiento sobre el martirio. Lo haremos -como en los artículos anteriores- ofreciendo una selección de textos de sus homilías, con alguna alusión a su Diario. El gran número de textos en que menciona el martirio y reflexiona sobre él y la riqueza teológica de los mismos, leídos y reflexionados veinte años después, es realmenle impactante y nos puede ayudar a la reflexión y vivencia de la fe en la actualidad.

De los textos impresionan varias cosas. Una es la libertad de espíritu con que Monseñor Romero habla de los "mártires» actuales, más allá del derecho canónico y de teologías oficiales. La otra es el aplomo con que habla de una realidad tan trágica como es el martirio -lo cual se aprecia mejor al escuchar sus homilfas. Por último impacta la lucidez y generosidad con que enfrenta exislencialmente el martirio, tanto el de su pueblo como el suyo propio.

Esta lucidez, Iranqueza y generosidad -como ocurre leyendo las palabras de Jesús en los evangelios- generó en su día ánimo y esperanza. Por ello, recordarlo hoy, hacer memoria de los mártires, no es simplemente mirar al pasado para quedarse anclados en él, prendidos en la nostalgia $-y$ mucho menos es masoquismo-, sino que es ayudar a proseguir los pasos y empujar la causa por la que

I. "Predicación y profecía. Análisis de las homillas de Monseñor Romero", Revista Latinoamericana de Teología 34 (1995) 3-36 "La predicación como prolongación del proyecto salvffico de Cristo en las homilfas de Monseñor Romero", id. 38 (1996) 99-139; "La autoridad en la Iglesia. Palabra y testimonio de Monseñor Romero", id. 40 (1997) 3-16 "Monseñor Romero y Medellín", id 45 (1998) 231-250. 
los mártires ofrendaron lo más valioso que tenían: su propia vida por la vida de los pobres. Y como la reflexión y el martirio de Monseñor Romero son todavía relativamente recientes, tienen el sabor de realidad, lo cual acrecienta la importancia de los textos.

Dividiremos el artículo en tres partes. En la primera presentaremos la reflexión de Monseñor Romero sobre la persecución y el martirio en la Iglesia y en el país, en la segunda, su reflexión sobre lo que podemos llamar «el pueblo crucificado». Los tres años de su misión pastoral y profética estuvieron, en efecto, marcados por la realidad del martirio. Su ministerio arzobispal comenzó con el asesinato del Padre Rutilio Grande y terminó con su propio martirio -y cntre ambos, el martirio del pueblo. El pueblo fue reprimido con violencia hasta la muerte. Los desaparecimientos, las masacres en manifestaciones de las organizaciones populares, los asesinatos selectivos de los dirigentes y las dirigentes populares, los asesinatos de catequistas, ellos y ellas, y de sacerdotes, fue el escenario cotidiano que le tocó vivir. Fue el perfodo cruel y violento que antecedió a la guerra civil, un período de represión contra el pueblo y de persecución contra la Iglesia.

¿Qué dijo Monseñor Romero en esas circunstancias? ¿Cómo actú́ la Iglesia que él dirigía? Visto todo en su conjunto, dos cosas impresionan hondamente. Una es que Monseñor Romero no evadió la realidad de muerte imperante y no dudó en llamar mártires a las víctimas. Es decir, por lo que toca a la realidad no dio un rodeo como los sacerdotes y levitas de la parábola, y por lo que toca a la interpretación teológica de las víctimas no se enredó en disquisiciones jurídicas y canónicas sobre si eran o no mártires. La otra es su visión del martirio, enraizada profundamente en el evangelio, que supera la reflexión tradicional de la Iglesia: quien es dado muerte como Jesús y por las mismas razones que Jesús ése es mártir. Y las masas inocentes que mueren masacradas y en total indefensión son el siervo sufriente de Yahveh, el pueblo crucificado. Todo ello sigue impactando hasta el día de hoy.

En la tercera parte presentaremos el testimonio personal de Monseñor Romero sobre su propio martirio. Así como Jesús fue consciente desde el principio de la persecución que podría sobrevenirle, pues comenzó su ministerio público "cuando fue apresado Juan Bautista» (Mc 1, 14), así Monseñor Romero, quien cornenzó precisamente cuando fue asesinado Rutilio Grande - junto con un anciano y un niño-, muy pronto se hizo consciente del peligro en que iba a vivir. En efeclo, desde el comienzo de su ministerio arzobispal, Monseñor junto con ataques y amenazas a personas, plataformas e instalaciones de la Iglesia- fue frecuentemente calumniado, perseguido y amenazado de muerte personalmente. Lo más hondo, sin embargo, es la conciencia que de que, al sufrir reacciones en su contra, estaba compartiendo el destino del pueblo: persecución, amenazas y, al fir Bibibaiaralirio.or Biblioteca "P. Florentino Idoate, S.J." 
En esta tercera parte es donde podemos encontrar, a mi juicio, los textos más impresionantes y hermosos de Monseñor Romero sobre el martirio. Son ante todo un testimonio personal, no sólo la reflexión teológico-pastoral de un arzobispo. Son el testimonio de un pastor que prometió públicamente a su pueblo que nunca lo abandonarfa.

\section{Reflexión de Monseñor Romero sobre los mártires salvadoreños}

Más que del martirio en abstracto Monseñor Romero habló de mártires concretos. Y es ahí, recordando a los mártires salvadoreños y pidiendo que se respetase su memoria, donde podemos encontrar reflexiones sobre el martirio que, leidas en su conjunto, pueden ofrecer una visión hasta cierto punto sistemática $y$, sobre todo, profundamente enraizada en el evangelio. Vamos a analizar cuatro ideas que se repiten constantemente en su predicación, y que consideramos de suma imporantancia. Monseñor Romero (1) no duda en reconocer como mártires a las víctimas de la violencia, (2) pide que se respete y celebre su memoria, (3) afirma que la persecución es una nota característica de la verdadera Iglesia, y (4) une el martirio de la Iglesia al martirio del pueblo. Veámoslo en textos importantes, a los que sólo añadiremos pequeños comentarios.

\subsection{Son verdaderos mártires}

En la celebración del primer aniversario del asesinato del P. Alfonso Navaпо, se refiere a él y al P. Rutilio Grande como "dos verdaderos mártires" ${ }^{2}$. Veamos primero el texto completo.

¿Por qué se mata? Se mata porque se estorba. Para mí que son verdaderos mártires en el sentido popular. Naturalmente, yo no me estoy metiendo en el sentido canónico, donde ser mártir supone un proceso de la suprema autoridad de la Iglesia, que lo proclame mártir ante la Iglesia universal. Yo respelo esa ley y jamás diré que nuestros sacerdotes asesinados han sido mártires canonizados. Pero sí son mártires en el sentido popular, son hombres que han predicado precisamente esa incardinación con la pobreza, son verdaderos hombres que han ido a los límites peligrosos donde la UGB amenaza, donde se puede señalar a alguien y se termina matándolo como mataron a Cristo. Estos son los que yo llamo verdaderamente justos. Y si tuvieron sus manchas, ¿quién nos las tiene hermanos? ¿Qué hombre no liene algo de qué arrepentirse? Los sacerdotes que han sido matados también han sido hom-

2. Cfr. Homilia 7 de mayo de 1978, IV, p. 211 . La cita completa dice asi: "Estos dos verdaderos mártires; porque esto significa mártir: el que ha sido matado en odio de

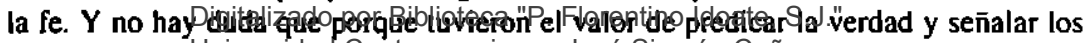

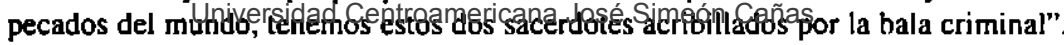


bres y tuvieron sus manchas. Pero el hecho de haber dejado que les quitaran la vida y no haberse huido, no haber sido cobardes y haberlos siluado en esa situación de tortura, de sufrimiento, de asesinato, para mí es tan valioso como un bautismo de sangre y se han purificado. ¡Tenemos que respetar su memoria! (Homilia 23 de septiembre de 1979, VП, p. 287).

En este texto, Monseñor Romero quiere salir al paso a quienes, o por ignorancia o por mala voluntad, lo atacan por llamar «mártion a las numerosas víctimas de aquella época. En cse contexto, distingue con finura y con sentido pastoral entre lo que es reconocimiento popular del martirio y lo que es reconocimiento olicial. Pero lo importante es su propósito: lejos de desacreditar a quienes Ilama mártires, a los que han caído, dando testimonio de entrega al pueblo y a Dios, se une a ellos. Y con gran valentía termina pidiendo que se respete la memoria de mártires y caídos, tan difamados en aquel tiempo. Pero, además, Monseñor justifica su visión pastoral, y ofrece una importante reflexión sobre lo que es el martirio.

Ante todo, para Monseñor el martirio tiene su último origen en la encarnación en los pobres; dicho más concretamente, el martirio proviene de mantenerse en esa encarnación y en la defensa de los pobres en contra de sus opresores. Eso es lo que «estorba», y la reacción son amenazas y muerte. Esa encarnación entre los pobres y su defensa es para Monseñor «la mayor virtud» del mártir -pudiéramos decir- en paralelo al «mayor amon de que habla el evangelio de Juan. Es io más valioso. Y por lo que toca a la «razón» del martirio, cuestión tan debatida teóricamente, con la inluición cristiana y teológica de que hizo gala con frecuencia, Monseñor dice lapidariamente: se les mata "como mataron a Cristo». Por simple que sea recordarlo, Monseñor encuentra en Cristo -en su muerte y en las razones que lo llevaron a ella- el criterio último y fundamental para poder llamar hoy «mártir» a una persona.

\subsection{Hay que mantener la memoria de los mártires}

En la tradición del «recuerda Israel» y del «hagan esto en recuerdo mío», Monseñor Romero siempre recordó a los mártires y nunca pasó por alto ningún aniversario de los mártires de su pueblo y de su Iglesia'. Así lo dijo solemne-

3. A continuación cilamos las homilías de Monseñor Romero en la misas de mártires y celebraciones de sus aniversarios. La lectura de las mismas nos podrá dar una visión muy completa de lo que Monseñor Romero pensaba sobre el martirio y los mártires: Rutilio Grande como hombre, como cristiano y como sacerdote. Homilía en el primer aniversario de la muerte del P. Rurilio Grande (El Paisnal, 5 de marzo de 1978, IV, pp. 67-73). Monseñor adelantó una semana la celebración de este aniversario para no coincidir con las elecciones legislativas. Un llamamiento a la unidad, la

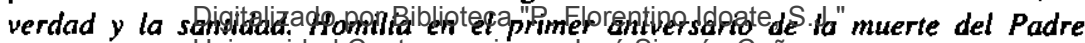
Universidad Centroamericana José Simeón Cañas 
mente en la celebración del primer aniversario del P. Rutilio Grande y de «sus compañeros de muerte», que coincidió con el aniversario de los «los caídos de La Libertad», mártires, «caídos políticos», podńamos decir":

Tenemos, hermanos, la obligación de recoger el recuerdo de nuestros queridos colaboradores, $y$, si han muerto bajo un signo martirial, recoger también su ejemplo de entereza, de valor, para que esa voz que quisieron acallar con la violencia no se muera, sino que siga siendo el grito de Jesucristo: 'No teman a los que sólo pueden matar el cuerpo', pero dejan vibrando la palabra y el mensaje eterno del evangelio (Homilía 26 de febrero de 1978, IV, p. 43).

Las palabras son fuertes. Hay «obligación» de mantener el recuerdo de los mártires y su ejemplo, en este caso «la entereza», tan necesaria para seguir viviendo cristianamente después de ellos. Pero, además, denuncia con clarividencia que sus asesinos quisieron -y quieren-callar esas voces. Por esa precisa razón promovió publicaciones para conocer la vida y testimonio de estos mártires

Esta reacción de Monseñor no era nada obvia, pues en aquellos años de represión y muerte sabía muy bien que la celebración de la memoria de los mártires y de los caf́dos era conflictiva. Y sabía que él mismo era cuestionado y acusado de «meterse en política» cuando celebraba esos aniversarios. Sin embargo, lejos de dar marcha atrás, mantiene con valentía la celebración de los aniversarios. Y como es atacado por ello, aclara, desde una perspectiva eclesial, los objetivos de estas celebraciones, que son tres: orar por los difuntos, consolar a los que lloran la separación de las víctimas y llamar a la conversión a los que han causado esas muertes ${ }^{6}$. A veces lo formula también desde la relación esencial entre Iglesia y pueblo. «El papel de la Iglesia en estos aniversarios, en estas

Alfohso Navarro (11 de mayo de 1978, IV, pp. 223-227). Homilla en el funeral del Padre Ernesto Barrera Motto (29 de noviembre de 1978, V, pp. 332-336). Un asesinato que nos habla de resurrección. Homilía ante el asesinato del Padre Ociavio Ortiz (21 de enero de 1979, VI, pp. 127-137). Homilia en el funeral del Padre Rafael Palacios (21 de junio de 1979, VII, pp. 7-12). Homilía del fin de novenario del Padre Rafael Palacios (30 de junio de 1979, VII, pp. 33-38). Homilia en la Misa de ireinta día del Padre Rafael Palacios (20 de julio de 1979, VII, pp. 93-98). También dedicó unas palabras a la memoria del Padre Alirio Napoleón Macias, en sus homilfas del 12 de agosto de 1979, VII, pp. 155-158, y 26 de agosto de 1979. p. 202. Como se puede apreciar, Monseñor Romero tuvo siempre muy presentes a los seis sacerdotes asesinados anles que él.

4. Se refiere a las victimas de la masacre contra manifestantes que protestaban por el fraude electoral, en el que resultó electo el presidente Romero ( $C f r$. Homilía 26 de

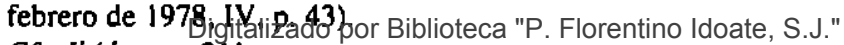

5. Cfr. Ibíden, p.URhl lersidad Centroamericana José Simeón Cañas

6. Cfr. Homilia 5 de marzo de 1978, IV, p. 54. 
celebraciones -que quede bien claro- es ser la voz. de los derechos humanos, la voz de la conciencia del pueblo, la oración que transciende hacia Dios»?

Al exigir mantener la memoria de los mártires es importante caer en la cuenta que Monseñor Romero no sólo recordó a los mártires sacerdotes, sino también a los catequistas, los agentes de pastoral y los miembros de las comunidades cristianas, y lo hacía con nombre y apellidos. $Y$ esto fue absolutamente central en su fe y en su ministerio pastoral. Por ello, aunque parezca que nos alargamos innecesariamente, citemos siquiera dos textos en los que Monseñor va desgranando un rosario de nombres de víctimas de la semana:

Yo quiero recordar aquí a nuestros queridos hermanos catequistas. Sería imposible enumerarlos a todos; pero recordemos por ejemplo a Filomena Puertas, a Miguel Martínez, a tantos otros, queridos hermanos, que han trabajado, que han muerto, y que en la hora de su dolor, de su agonía dolorosa, mientras los despellejaban, mientras los torturaban y daban su vida, mientras eran ametrallados, subieron al cielo. ¡Y están allá victoriosos! ¿Quién ha vencido? Como la Biblia podemos preguntar a los que los mataron y a los que siguen persiguiendo a los cristianos: ¿dónde está, oh muerte, tu victoria? La victoria es la de la fe. Han salido victoriosos los matados por la justicia (Homilia 30 de octubre de 1977, I-II, pp. 300-301).

El sábado 26, ayer, en Tejutla, al celebrar el primer aniversario de Felipe de Jesús Chacón, también me di cuenta que nuestra tierra le ofrece al Papa, como lo dije en mis visitas pasadas, ¡mártires! ¡Qué horror cuando me contaban! El rostro despellejado de Felipe de Jesús, y lo que es peor, difamado en la prensa como un cuatrero, cuando se trata de un catequista valiente, que supo llevar el evangelio hasta sus consecuencias más arriesgadas (Homilía 27 de agosto de 1978, V, p. 154).

Varios comentarios pueden hacerse a estos dos textos impresionantes: la convicción del triunfo de las víctimas sobre los verdugos, el horror de las torturas y las difamaciones, la valentía de ofrecerle al Papa la realidad del país, y de no ocultarla como se ha hecho tan frecuentemente. Pero lo fundamental es no perder ninguno de los nombres, aunque eso alargara la homilía. Y -en el segundo texto- mostrar el gran sentimiento que tenía por Felipe de Jesús, «despellejado como san Bartolomé por proclamar el evangelio», como dijo en el segundo aniversario (Homilía 26 de agosto, 1979, p. 209). Y lo más fundamental es el amor que sentía por ellos. «Yo le he llorado de veras y con ellos a otros muchos que fueron catequistas, trabajadores de nuestras comunidades, hombres muy cristianos" (Entrevista a Prensa Latina, 15 febrero de 1980; citado en La Voz de los $\sin$ voz, San Salvador, 1980, p. 443).

7. Ibidem, p. 55. Digitalizado por Biblioteca "P. Florentino Idoate, S.J." Universidad Centroamericana José Simeón Cañas 


\subsection{La persecución es una nota de la verdadera Iglesia}

Monseñor Romero habló mucho y bien de la Iglesia, pero cuando fue a lo fundamental habló de la Iglesia de los mártires. Una Iglesia verdadera debe trabajar por superar el pecado, por supuesto, pero además debe trabajar por superar el docetismo, debe ser verdadera sarx, carne salvadoreña, como suele decir Jon Sobrino. Por ello, si se encarna en un mundo de pecado, en el que el maligno es asesino y mentiroso -como dice Juan-, la Iglesia verdadera debe sufrir las consecuencias en forma de asesinato y calumnia. Eso es lo que hace a la Iglesia salvadoreña y lo que la hace cristina. Esto fue evidente para Monseñor Romero, y lo dijo con palabras que no sabemos si tienen parangón en la historia: los mártires son la expresión de una Iglesia que ha hecho la opción por los pobres, de una Iglesia encarnada y comprometida con ellos. Son expresión de la verdadera Iglesia, la Iglesia de Jesús. En palabras escalofriantes dijo:

Me alegro, hermanos, de que nuestra Iglesia sea perseguida precisamente por su opción preferencial por los pobres y por tratar de encarnarse en el interés de los pobres y decir a todo el pueblo, gobernantes, ricos y poderosos: si no se hacen pobres, si no se interesan por la pobreza de nuestro pueblo como si fuera su propia familia, no podrán salvar a la sociedad (Honilia 15 de julio de 1979, VII, p. 79).

Estas palabras, aparentemente absurdas y escandalosas, debieran ser elementales en una Iglesia de Jesús, pues no dicen otra cosa que la Iglesia debe asemejarse a su fundador. En la vida real, sin embargo, son todo menos evidentes. Por ello, aunque nos alarguemos, vamos a reproducir algunos textos más, sin mucho comentario, sobre la idea central de Monseñor Romero: nota fundamental de la veradera Iglesia es «ser perseguida». Veamos primero los textos.

La persecución es algo necesario en la Iglesia. ¿Saben por qué? Porque la verdad siempre es perseguida. Jesucristo lo dijo: «Si a mí me persiguieron, también a ustedes les perseguirán». Y por eso, cuando un día le preguntaron al Papa León XIII, aquella inteligencia maravillosa de principios de nuestro siglo, cuáles son las notas que distinguen a la Iglesia católica verdadera, el Papa dijo ya las cuatro conocidas: una, santa, católica y apostólica. «Agreguemos otra -les dice el Papa-, perseguida». No puede vivir la Iglesia que cumple con su deber sin ser perseguida (Homilía 29 de mayo de 1977, I-II, p. 73).

La Iglesia no puede callar ante esas injusticias del orden económico, del orden político, del orden social. Si callara, la Iglesia serfa cómplice con el que se margina y duerme un conformismo enfermizo, pecaminoso, o con el que se aprovecha de ese adormecimiento del pueblo para abusar y acaparar

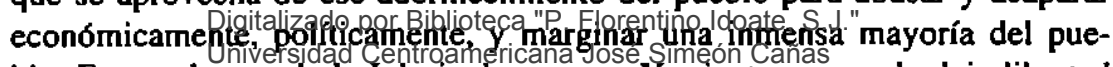
blo. Esta es la voz de la Iglesia, hermanos. Y mimutras no se le deje libertad 
de clamar estas verdades de su evangelio, hay persecución. Y se trata de cosas sustanciales, no de cosas de poca importancia. Es cuestión de vida o muerte para el reino de Dios en esta tierra (Homilia 24 de julio de 1977,I-II, p. 142).

Hermanos, no nos debe de extrañar cuando se habla de Iglesia perseguida. Muchos se escandalizan y dicen que estamos exagerando, que no hay Iglesia perseguida. ¡Pero si es la nota histórica de la Iglesia! Siempre tiene que ser perseguida. Una doctrina que va contra las inmoralidades, que predica contra los abusos, que va siempre predicando el bien y atacando el mal, es una doctrina puesta por Cristo para santificar los corazones, para renovar las sociedades. $Y$, naluralmente, cuando en esa sociedad o en ese corazón hay pecado, hay egoísmo, hay podredumbres, hay envidias, hay avaricias, pues el pecado salta, como la culebra cuando tratan de apelmazarla, y persigue al que trata de perseguir el mal, el pecado. Por eso, cuando la Iglesia es perseguida es señal de que está cumpliendo su misión (Homilía 25 de noviembre de 1977, I-II, p. 339).

Primero la persecución trata de halagar, de domesticar; y cuando uno se doblega ante estos halagos, pues no hay necesidad de perseguirlo, ya está vencido. Por eso, mucho cuidado, queridos hermanos, no se dejen halagar. Cuando el halago viene del pecado, y cuando se trata de no molestarse, de no sacrificarse, de estar bien, de instalarse cómodamente en la tierra. eso es malo, porque entonces ya uno se hizo también perseguidor (Homilía 25 de noviembre de 1977, I-II, p. 340).

Estos textos están citados en orden cronológico. Si hacemos un pequeños esfuerzo de sistematización, quizás se pueden resumir de esta manera. En primer lugar, la persecución es necesaria a la Iglesia de Jesús, afirmación fundamental e impresionante que no escamotea Monseñor. Esto no significa caer en sacrificialismos o martirialismos, y por eso Monseñor da la razón de tan grave afirmación. La Iglesia -dice- no puede callar ante las aberracciones de la sociedad; no es lo suyo, pues, denunciar sólo los pecados del individuo. $Y$ no puede callar, pues hacerlo es pecado grave, es convertirse en cómplice de dichas aberraciones. Los poderes de este mundo la halagarán para ponerla de su lado, para domesticarla y silenciarla, pero «no se dejen halagan. Cuando la Iglesia cae en esa trampa, ella misma se convierte en perseguidora. Superada la tentación del halago, y sean cuales fueren las consecuencias y los costos, la Iglesia debe hablar, tiene como obligación sagrada decir la verdad.

Todo esto significa enfrentarse y desenmascarar al Maligno que es mentiroso. Y cuando éste se siente amenazado reacciona según su esencia: es asesino. De ahi proviene la necesidad de que la Iglesia sea perseguida: 
La persecución es una nota característica de la autenticidad dela Iglesia. Una Iglesia que no sufre persecución, sino que está disfrutando de los privilegios y el apoyo de las cosas de la tierra, ¡tenga miedo!, no es la verdadera Iglesia de Jesucristo (Homilia 11 de marzo de 1979, VI, p. 190).

\subsection{Estrecha relación entre mártires y caídos}

La razón por la cual Monseñor alaba tanto el martirio es por ser la consecuencia de encarnarse en el interés de los pobres, por mostrarles amor, por ser para ellos -hasta el final- como Jesús fue -hasta el final- para los pobres de su tiempo. Pero si ésa es la razón fundamental de la excelencia del martirio, entonces se entiende también que Monseñor Romero tenga palabras de admiración para «los que caen en la lucha» del pueblo. Se refiere a tantas mujeres y hombres que en las organizaciones populares reinvidicaron los derechos del pueblo y lucharon por mejorar sus condiciones de vida. Las masacres de manifestaciones populares y los asesinatos de dirigentes de las organizaciones del pueblo fueron la respuesta del gobiemo y de los poderosos a las justas reivindicaciones de aquéllos, y desde ahí hay que entender la reacción fundamental de Monseñor Romero:

A quienes caen en la lucha, con tal que sea con sincero amor al pueblo y en busca de una verdadera liberación, debemos considerarlos siempre entre nosolros (Homilia 27 de enero de 1980. VIII, p. 202).

No pensemos, hermanos, que nuestros muertos se han apartado de nosolros; su cielo, su recompensa eterna, los perfecciona en el amor, siguen animando las mismas causas por las que murieron. Lo cual quiere decir que en El Salvador esta fuerza liberadora no sólo cuenta con los que van quedando vivos, sino que cuenta con todos aquellos que les han querido matar y que están más presentes en este proceso del pueblo (Homilía 2 de marzo de 1980, VII, p. 259).

Con estas palabras, Monseñor está sancionando la bondad y nobleza de todas las muertes, las de los llamados mártires y las de los llamados caídos -lo cual le acarreaba mayor indignación de parte de sus enemigos. Probablemente sin saberlo, estaba recogiendo, de hecho, la noción que tenía santo Tomás sobre la bondad del martirio: el elemento formal del martirio y lo que le otorga excelsitud es el amor. Y por eso, allá donde Monseñor veía verdadero amor al pueblo, amor que llevaba a la muerte, vela martirio. $Y$ eso le posibilitó lo que no suele ser nada común en la Iglesia: unificar el martirio de la Iglesia con el martirio del pueblo. Y esto, además, visto desde la Iglesia, le produjo una gran alegría: el que se mezcle la sangre del pueblo con la de la Iglesia es lo que la hace verda-

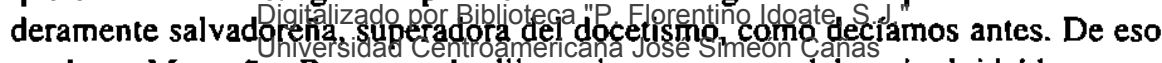
se alegra Monseñor Romero y lo dijo varias veces en palabras inolvidables: 
Podemos presentar junto a la sangre de maestros, de obreros, de campesinos, la sangre de nuestros sacerdotes. Esto es comunión de amor. Sería triste que en una patria donde se está asesinando tan horrorosamente no contáramos entre las víctimas también a los sacerdotes. Son el testimonio de una Iglesia encarnada en los problemas del pueblo (Homilia 30 de junio de 1979, VII, p. 37).

Mezclar la sangre de la Iglesia con la sangre del pueblo es tema que Monseñor Romero repitió varias veces. En realidad, significa unir dos dimensiones de un mismo martirio. El uno explica al otro:

La Iglesia sufre el destino de los pobres: la persecución. Se gloría nuestra Iglesia de haber mezclado su sangre de sacerdotes, de catequistas y de comunidades, con las masacres del pueblo y haber llevado siempre la marca de la persecución. Precisamente porque estorba, se la calumnia y no se quisiera escuchar en ella la voz que reclama contra la injusticia (Homilia 17 de febrero de 1980, VIII, p. 235).

Cristo nos invita a no tener miedo a la persecución, porque, créanlo hermanos. el que se compromete con los pobres tiene que correr el mismo destino de los pobres. Y en El Salvador ya sabemos lo que significa el destino de los pobres: ser desaparecidos, ser torlurados, ser capturados, aparecer cadáveres (Homilia 17 de febrero de 1980, VIII, p. 240).

Desde la realidad histórica de los pobres, Monseñor vio la necesidad de que la Iglesia participase en el destino de todos aquellos que han hecho suya su causa. Pero también desde la realidad de Cristo hay que comprometerse con los pobres. Y así, quienes se encuentran juntos en esa tarea, derramando su sangre por los pobres, bien pueden ser llamados cristianos, explícitos o anónimos.

\section{EI pueblo crucificado}

Hasta ahora hemos hablado de mártires individuales y activos, aquellos que. generosamente, en la Iglesia o en el pueblo, entregan consciente, generosa y libremente su vida por la liberación de los pobres. ¿Pero qué decir de las víctimas masivas de la represión, de los cientos y miles que fueron asesinados en masacres, «mártires anónimos», cuyo delito fue ser pobres? ¿O qué decir de los salvadoreños que mueren lentamente, día a día, por causa de la injusta pobreza?

Sea cual fuere la teologización de estas realidades, hay que decir, antes que nada, que Monseñor Romero los tuvo centralmente en cuenta, y los hizo una realidad central para la fe, pues ellos son «el pueblo crucificado»:

Sentimos en el Cristo de la semana santa, con su cruz a cuestas, que es el pueblo que va cargando también su cruz. Sentimos en el Cristo de los brazos

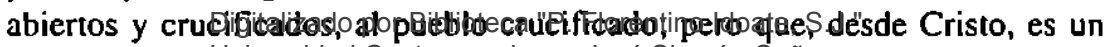
Universidad Centroamericana José Simeón Cañas 
pueblo crucificado y humillado que encuentra su esperanza (Homilia 19 de marzo de 1978, IV, p. 80).

Es nuestro pueblo torturado, es nuestro pueblo crucilicado, escupido, humillado al que representa Jesucristo nuestro Señor, para darle a nuestra siluación tan difícil un sentido de redención (Honilia 24 de marzo de 1978, IV, p. 193).

En Cristo encontramos el modelo del liberador, hombre que se identifica con el pueblo, hasta llegar los intérpretes de la Biblia a no saber si el Siervo de Yahvéh, que proclama Isaías, es el pueblo sufriendo o es Cristo que viene a redimirnos (Homilía 21 de octubre de 1979, VII, p. 373).

Monseñor Romero identifica al pueblo que sufre con Cristo crucificado y con el siervo sufriente de Yahvé. Y, como Ignacio Ellacuría, recalca dos cosas: en primer lugar, el hecho en sí mismo -cosa olvidada en la Iglesia y en la teologia-, y en segundo lugar el significado salvífico del hecho -cosa todavía mas olvidada. Veamos algunas de las reflexiones de Monseñor ante el pueblo crucificado.

\subsection{Ante todo, hay que defender la vida}

Para Monseñor Romero, el pueblo crucificado «loca el corazón de Dios». Si Monseñor denuncia la represión contra el pueblo es porque «nada hay tan importante como la vida humanam. La idea la repite sin cesar:

Una vez más el Señor pregunta a Caln: ¿dónde está Abel, tu hermano? Y aunque Caín le responde al Señor que no es el guardián de su hermano, el Señor replica: «La sangre de tu hermano me está gritando desde la tierra. Por eso te maldice esta tierra, que ha abierto sus fauces para recibir de tus manos la sangre de tu hermano. Aunque cultives la tierra, no te pagará con su fecundidad, andarás errante y perdido en el mundo». Palabras del Génesis en el capílulo 4. Y esta sigue siendo la preocupación principal de la Iglesia, esto es lo que la obliga a levantar incesantemente, incansablemente, semana tras semana, su voz como si fuera voz que clama en el desierto. Nada hay tan importante para la Iglesia como la vida humana, como la persona humana. Sobre todo, la persona de los pobres y oprimidos, que además de seres humanos son seres divinos, por cuanto dijo Jesús, que todo lo que con ellos se hace, él lo recibe como hecho a él. Y esa sangre, la sangre, la muerte, están más allá de toda política, tocan el corazón mismo de Dios, hace que ni la reforma agraria, ni la nacionalización de la banca, ni otras prometidas medidas puedan ser fecundas si hay sangre (Homilía 16 de marzo de 1980, VIII, p. 348).

Digitalizado por Biblioteca"P. Florentino Idoate, S.J.

Universidad Centroamericana José Simeón Cañas 
Este es el pensamiento fundamental de mi predicación: nada me importa tanto como la vida humana. Es algo tan serio y tan profundo, más que la violación de cualquier otro derecho humano, porque es vida de los hijos de Dios y porque esa sangre no hace sino negar el amor, despertar nuevos odios, hacer imposible la reconciliación y la paz. ¡Lo que más se necesita hoy aquí es un alto a la represión! (Homilia 16 de marzo de 1980, VIII, pp. 348-349).

\subsection{La maldad del pecado: la muerte}

La condena de la muerte fue constante en Monseñor Romero, pero lo hizo con especial vehemencia cuando la muerte iba acompañada de tortura y sadismo, de modo que los cadáveres se parecían literalmente al siervo doliente de Yahveh, "varón de dolores», sin rostro ni figura, sin nadie que defienda su causa.

La muerte es signo de pecado, cuando la produce el pecado tan directamente como entre nosotros: la violencia, el asesinato, la tortura donde se quedan tantos muertos, el machetear y tirar al mar, todo eso es el imperio del infierno. Son del diablo los que hacen la muerte. La experimentan los que le pertenecen al diablo. Colaboradores, agentes del demonio, impostores de algo extraño que no cabe en el plan de Dios. Por eso, la Iglesia no se cansará de denunciar todo aquello que produce muerte. La muerte, aun la muerte natural, es producto y consecuencia del pecado (Homilía I de julio de 1979 , VII, pp. 41-42).

Siguen matando maestros. Continúan apareciendo cadáveres no identificados en distintas partes del país. Son tantos los que han muerto así, que ya se hace difícil hasta mencionar sus nombres o la vertiente política a la que pertenecen. Pero todos denuncian una danza macabra de venganza, de una violencia institucionalizada, pues unos mueren así directamente víctimas de la represión y otros mueren precisamente por servir a esa represión. Podemos decir que nuestro sistema es como aquel dios Moloc, insaciable en cobrarse víctimas, ya sea los que están contra él, ya sea también los que le sirven. Así paga el diablo. Por eso, cuando se me dice que yo sólo me fijo en una clase de muertos y no en otros, yo digo: jla muerte me duele tanto en cualquier hombre que sea! Esta danza macabra de la muerte por venganza política, es el mejor índice, espantoso índice, de lo injusto de nuestro sistema (Homilio 1 de julio de 1979, VII, p. 42).

Monseñor Romero compara el sistema al dios Moloc, divinidad mítica del pasado que sigue existiendo históricamente. Esas falsas divinidades son los ídolos que exigen víctimas para subsistir. $Y$ en el siguiente texto retoma una idea

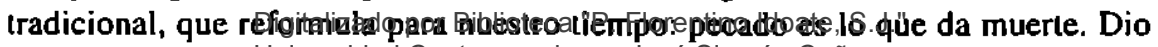
Universidad Centroamericana José Simeón Cañas 
muerte a Cristo, el Hijo de Dios, y sigue dando muerte real a los hombres y mujeres de hoy, hijos e hijas de Dios, sobre todo y masivamente a los pobres.

Así es el pecado, es muerte. Por eso, donde quiera que hay muerte, hay pecado. La muerte es la señal evidente de que el pecado reina. Espanta pensar que en la patria haya tantos muerlos y que los caminos sagrados de nuestro suelo se empapan cada vez más de sangre humana. El pecado reina en El Salvador y los liberadores de El Salvador tienen que comenzar por allí: cómo amancar el pecado de nuestro suelo (Homilía 2 de marzo de 1980, VIII, pp. 292-293).

\subsection{El amor al pueblo crucificado: que nadie quede sin nombre}

Ese pueblo crucificado, masivo, está hecho para Monseñor Romero de nombre concretos. No hay muertos "anónimos». Todos los que violentamente eran despojados de sus vidas tenían para Monseñor Romero un nombre y un apellido. En todas sus homilías los nombra, consuela a sus familias, describe las circunstancias de su muerte, denuncia los mecanismos del horror, llama a la conversión. Basta leer sus homilías para percatarse de ello.

En este sentido profundo, las homilias de Monseñor Romero fueron el primer Informe de la Comisión de la Verdad que dejó al descubierto los mecanismos del horror, los nombres de las víclimas y los responsables de esos asesinatos. Los ejemplos que citamos son extensos, pero, dado lo nuevo que resultaba predicar de esa forma, es necesario aducirlos para captar la importancia decisiva que para Monseñor Romero tenía la vida de cada persona:

El 21 de febrero en Suchitoto fueron emboscados por reconocidos miembros de ORDEN los campesinos Jeremías Melgar y Osmaro Acosta, ambos fueron asesinados. El último es pariente cercano del campesino Lucio Elías Acosta, asesinado en iguales circunstancias el 13 de febrero. También ese día, el 21 de febrero, en Aguilares, cantón de Amayo, fueron asesinados por miembros de ORDEN, protegidos por cuerpos de seguridad, los campesinos Teodoro Vega, Miguel Angel Rivas Ruiz, Manuel Marroquín y Carlos Alvarado. Fue asesinado otro profesor, José Abilio Torres Benavides. Y ya en lo que va de este año, son nueve los profesores asesinados. También por sentido de amistad, quiero solidarizarme con el dolor de la familia del señor Edgar Béneke, arrollado en esta ola de violencia de nuestro país... El campesino Gabriel Antonio Menjívar Cornejo y Francisco Molina, capturados el 14 de febrero en Aguilares por 20 agentes de civil de la Policía de Hacienda; los campesinos Candelario Jesús Alas, Silvestre Landaverde Cardoza, Pastor Escalante Escobar, Roberto Antonio Villanueva, capturados en Aguilares por

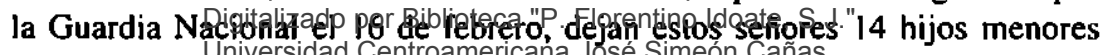
en orfandad; los campesinos Carlos Amilcar y Rafael Antonio Linares, cap- 
turados el 14 de febrero, en San Salvador; la campesina María del Carmen Pérez, capturada el 15 de febrero, en San Salvador, cerca del mercado municipal; el licenciado Jaime López y el señor Oscar René Aparicio, capturados el 19 de febrero de 1980, en San Vicente. Al entrar aquí también llorosa, la madre de Francisco Arnulfo Ventura, capturado el 22 de enero y todavía sin aparecer. Pide misericordia para su hijo y para ella (Homilia 24 de febrero de 1980, VIII, p. 273).

En el cantón Mogotes, jurisdicción de Tacachico, la represión fue más cruel, pues las tropas de soldados con dos tanquetas sembraron el terror entre los habitantes de este sector. En el cateo que realizaron, se robaron cuatro radios y cuatrocientos colones en efectivo, quemaron la casa y todas las pertenencias de Rosalío Cruz, a quien junto con su familia los han dejado en la peor miseria. Asesinaron a Alejandro Mojica y a Félix Santos. Al primero en su casa de habitación y al segundo en una quebrada seca. Ambos dejaron esposas e hijos en la orfandad. Por temor a la represión fueron enterrados en sus respectivos solares, se llevaron también con rumbo desconocido a Isabel Cruz, a Manuel y a Santos Urquilla (Homilía 23 de marzo de 1980, VIII, p. 381).

\subsection{La suma maldad: enfrentar a los pobres entre sí}

Los textos que siguen a continuación quieren desmentir a quienes acusaban a Monseñor de fijarse solamente en las víctimas de un bando, pero, al defenderse, denuncia lo que le llenó de especial dolor: los mecanismos que llevaron a enfrentarse a los pobres entre sí.

Uno de los pecados más grandes es éste, hermanos, que a mí me duele tanto: que el sistema actual de nuestra patria ha logrado el enfrentamiento de los campesinos. El mismo hambre, que angustia al hombre del Bloque, es el mismo hambre que angustia tambien al hombre de ORDEN. Y pensar también que el agente de nuestros ejércitos ha salido también del campesinado. $\mathrm{Y}$ cuando miro policías cuidando a campesinos, campesinos cuidando a campesinos, ORDEN enfrentándose con el Bloque, digo yo: ¡qué satánico ha tenido que ser este sistema que ha logrado aprovechar el hambre de los hombres, el ganarse el pan, aunque sea persiguiendo, enernistándose, dividiéndose, cuando pertenecen a la misma pobreza! (Homilía 16 de abril de 1978, IV, p. 167).

Textos como éste no ayudan sólo ni principalmente para afinar el concepto, sino para mostrar el gran amor del que surgen. De otra forma, recogen la gran afimación de Monseñor Romero: «la gloria de Dios es que el pobre viva». En el enfrentamiento entre hermanos Monseñor vio la negación más triste de Dios.

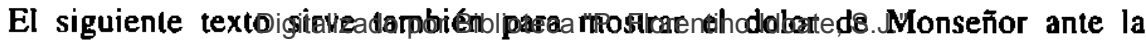


muerte de cualquier ser humano, especialmente de los pobres, sea del bando que fucre, y para ver cómo clamaba para poner fin al mortal enfrentamiento fralricida:

Tenemos que lamentar esta semana también la muerte de dos policías. Son hermanos nuestros. Ante el atropello y la violencia, jamás he parcializado mi voz. Me he puesto, con compasión de Cristo. al lado del muerto. de la víclima, del que sufre, y he pedido que oremes por ellos, y nos unimos en solidaridad de dolor con sus familias. He dicho que dos policías que mueren, son dos víclimas más de la injusticia de nuestro sistema que, denunciaba el domingo pasado, entre sus crímenes más grandes logra confrontar a nuestros pobres. Policías y obreros o campesinos pertenecen todos a la clase pobre. La maldad del sistema en lograr el enfrentamiento de pobre contra pobre. Dos policías muertos son dos pobres que han sido víctimas de otros tal vez pobres también, y que en todo caso son víctimas de ese dios Moloc, insaciable de poder, de dinero, que con tal de mantener sus situaciones injustas no lc importa la vida ni del campesino, ni del policía, ni del guardia, sino que lucha por la defensa de un sistema lleno de pecado (Homilía 30 de abril de 1978, IV, p. 193).

\subsection{La salvación que trae el pueblo crucificado}

A Monseñor Romero le dolió hondamente la suerte de su pueblo, pero insistió en repetidas ocasiones en el carácter redentor del dolor y sufrimiento del pueblo, así como Ellacuría analizó el potencial de salvación histórica del siervo. Esto para nada indica una actitud pasiva y de resignación ante el sufrimiento como él mismo lo condena-, pero sí expresa la fe de Monseñor Romero, cuando ésta se adentra en el misterio del siervo sufriente:

Hay mucho sufrimiento, hay muchos hogares destrozados, hay mucho dolor, hay mucha pobreza. Hermanos, todo eso no lo miremos con demagogia. El Dios de los pobres ha asumido todo eso y le está enseñando al dolor humano el valor redentor, el valor que tiene para redimir al mundo la pobreza, el sufrimiento, la cruz. No hay redención sin cruz. Pero esto no quiere decir un pasivismo de nuestros pobres, a los que hemos mal adoctrinado cuando les decimos: «Es la voluntad de Dios que seas pobre, marginado y no tienes esperanzas. ¡Eso no! Dios no quiere esa injusticia social; pero si una vez que existe se da como un tremendo pecado de los opresores $-y$ la violencia más grande está en ellos que privan de felicidad a tanto ser humano y que están matando de hambre a tanto desnutrido-, Dios reclama justicia, pero le está diciendo al pobre, como Cristo al oprimido, cargando con su cruz, salvarás al mundo si le das a tu dolgr no un conformismo que Dios no quiere, sino

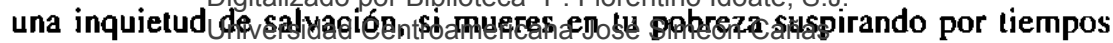
mejores, haciendo de tu vida una oración y acuerpando todo aquello que 
trata de liberar al pueblo de esta situación (Homilia 24 de diciembre de 1979, VIII, p. 84).

En un difícil acto de re, como el cantor del siervo, Monseñor ve que el pueblo crucificado trae salvación. La sangre derramada del pueblo es, escandalosamente, motivo de esperanza. He aquí un texto de poco antes de su martirio, verdadero himno a la esperanza.

Como Pastor y como ciudadano salvadoreño me apena profundamente el que se siga masacrando al sector organizado de nuestro pueblo, sólo por el hecho de salir ordenadamente a la calle para pedir justicia y libertad. Esloy seguro que tanta sangre derramada y tanto dolor causado a los familiares de tantas víctimas no será en vano. Es sangre y dolor que regará y fecundará nuevas y cada vez más numerosas semillas de salvadoreños que tomarán conciencia cle la responsabilidad que tienen de construir una sociedad más justa y humana, y que fructificará en la realización de las reformas estructurales audaces, urgentes y radicales que necesita nuestra patria (Homilia 27 de enero de 1980, VIII, p. 202).

\section{El testimonio martirial de Monseñor Romero}

En medio de tanta persecución y muerte, Monseñor Romero, como Jesús, luvo que pensar también en lo que le podía ocurrir a él. Y así lo hizo, como veremos a continuación. Ahora sólo quisiera recalcar que, también en esto, se pareció a Jesús.

Monseñor Romero fue difamado como Jesús, a quien llamaban «comilón y bebedor», «arnigo de pecadores», «poseído por Belzebub». Fue perseguido, como Jesús, a quien, ya en el principio de su misión, Iras curar en sábado, los fariseos y herodianos querían eliminar. Y, sobre todo, como Jesús, permaneció fiel hasta el final a los pobres. El martirio de Monseñor Romero es su máxima palabra de libertad, de solidaridad y de amor a su pueblo. Y es, paradojicamente, la máxima expresión de su esperanza de que la vida triunfará. Veámoslo, brevemente, en sus propias palabras.

\subsection{Fotaleza ante la campaña de difamación}

Monseñor Romero fue nombrado arzobispo de San Salvador porque había hechos «méritos» para ello. Su pensamiento conservador y su amistad con familias influyentes y ricas eran una garantía para el gobierno y los ricos. Sin embargo, tras el asesinato de Rutilio Grande Monseñor comienza su misión tomando distancia del gobierno. Los ricos, sorprendidos por el cambio, no salían de su asombro: aquel a quien ellos habfan propuesto como el candidato ideal para

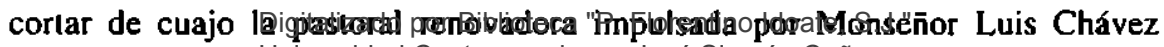


González y su auxiliar Monseñor Rivera les da la espalda. Ellos, por supuesto, no reconocen en este cambio una conversión, sino el producto de una manipulación. Monseñor Romero comienza su misión bajo una fuerte presión, y comienza conira él la campaña más masiva, irracional y cruel de difamación que se ha conocido en el país.

En esta situación, Monseñor Romero sabía que era prácticamente inútil explicar la verdad de su actuación, dada la irracionalidad de la campaña, pero, como Jesús, lo intentó siempre.

Estoy recibiendo muchos anónimos verdaderamente groseros. Sepan, hermanos, que la posición que he tomado está a base de conciencia. No es sólo de presiones, como se dice; sino simplemente el deber de un pastor que siente la alegría, al mismo tiempo que la angustia, de vivir con su pueblo. Y desde el pueblo, riel a la voluntad de Dios, caminar por un camino que sea verdaderamente el camino del Señor (Homilia 9 de octubre de 1977, I-I, pp. 265-266).

¿De dónde venían las presiones? Es conocido, pero hay que recordarlo. Monseñor Romero recibió muchas presiones -y también la izquierda quiso tenerlo de su lado. Pero la presión fundamental no provenía de los sectores de la izquierda, sino de la derecha y de círculos eclesiásticos. Así, lo deja entrever este texto -dado su contexto-, que expresa también hondo dolor.

¡Qué terribles son las presiones cuando nos quieren apartar de lo que Dios quiere, para que hagamos como los hombres quieren (Homilia 3 de septiernbre de 1978, V, p. 162).

Como ocurre con frecuencia en instancias eclesiásticas, estas presiones venían revestidas de una mal entendida prudencia. Sin embargo, en la realidad, la prudencia era una invitación a dejar pasar los hechos, a evitar los temas espinosos, a no hacer nada. Monseñor Romero desenmascaró este tipo de prudencia como una traición al evangelio:

La cruz provoca en el mismo Cristo la defensa de su misión, que es cruz y sacrificio. Qué fácil era seguir como Pedro, huir como andan huyendo hoy muchos cristianos. Es más fácil esconderse. «No hay que crear conflictos, prudencia, hay que ser más prudentes». Pero Cristo no fue de ese parecer y a quien le aconsejó no meterse en el peligro lo llamó Satanás, lo llamó escándalo (Homilia 3 de septiembre de 1978, V, p. 162).

Monseñor Romero era consciente de que su predicación caía mal a los círculos de poder y sabía también que caía muy bien al pueblo. Pero nunca trató de buscar falsos equilibrios para contentar a unos y a otros. Ni se escudaba -lo que

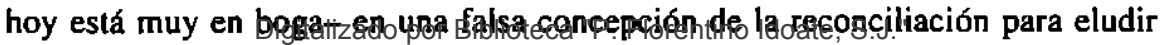
la misión proféticaldreelaidglesiantroamericana José Simeón Cañas 
Si uno vive un cristianismo que es muy bueno, pero que no encaja con nuestro liempo, que no denuncia las injusticias, que no proclama el reino de Dios con valentía, que no rechaza el pecado de los hombres, que consiente, por cstar bien con ciertas clases, los pecados de esas clases, no está cumpliendo su deber, está pecando, está traicionando su misión. La Iglesia está puesta para convertir a los hombres, no para decirles que está bien todo lo que hacen; y por eso, naturalmente, cae mal. Todo aquel que nos corrige, nos cae mal. Yo sé que he caído mal a mucha gente, pero sé que he caído muy bien a todos aquellos que buscan sinceramente la conversión de la Iglesia (Homilía 21 de agosto de 1977, I-II, p. 190).

Como consecuencia de esa su lidelidad al evangelio, Monseñor fue acusado de ser persona confrontativa y conflicliva. Su predicación fue frecuentemente acusada de provocar el enfrentamiento y de instigar a la rebeldía. Ante ello Monseñor tenía dos respuestas. Una la formulaba evangélicamente: «El evangelio es conflictivo». La otra es todavía más original y representa algo medular en su pensamiento y lestimonio: «estar del lado del pueblo que sufre».

Simplemente mantengo una posición de que no estoy confrontándome con nadie, sino que estoy tratando de servir al pueblo. Y el que esté en conflictos con el pueblo sí estará en conflictos conmigo. Pero mi amor es el pueblo; y desde el pueblo pueden ver, a la luz de la fe y del mandato que Dios me ha dado de conducir a este pueblo por los caminos del evangelio, quiénes están conmigo y quiénes no están conmigo, viendo simplemente las relaciones con el pueblo (Homilía 20 de agosto de 1978, V, p. 134).

Fíjense que el conflicto no es entre la Iglesia y el gobierno. Es entre gobierno y pueblo. La Iglesia está con el pueblo y el pueblo está con la Iglesia, igracias a Dios! (Homilía 21 de enero de 1979, VI, p. 137)

Además de ser parcial, arbitrario y antievangélico, Monseñor Romero también fue acusado de ser responsable de la violencia en El Salvador. A veces se decía de él que era su máximo responsable. Lo tildaban de «obispo revolucionario», con lo cual iba en aumento el peligro real contra su vida. Y, por cierto, todavía hoy hay políticos y obispos en nuestro pafs que así lo piensan y declaran. Monseñor replicaba:

Yo tengo la conciencia muy tranquila de que jamás he incitado a la violencia. Todos esos campos pagados y esas calumnias y esas voces de radio gritando contra el obispo revolucionario son calumnias, porque mi voz no se ha manchado nunca con un grito de resentimiento ni de rencor. Grito fuerte contra la injusticia, pero para decirle a los injuslos: ¡conviértanse! Grito en nombre del dolor para decirle a los criminales: ¡conviértanse! ¡No sean malos! (Homilia 1 de diciembre de 1977, III, p. 15).

8. Cfr. Homilia 21 desitalizado por Biblioteca "P. Florentino Idoate, S.J." 
Así reaccionaba Monseñor Romero hacia afuera, pero ¿se puede barruntar que sentía por dentro? Jamás guardó rencor hacia sus enemigos que lo calurnniaban con saña. Al contrario, les dijo que los amaba y los invitó a la conversión.

Queridos hermanos, sobre todo ustedes mis queridos hermanos que me odian, ustedes mis queridos hermanos que creen que yo estoy predicando la violencia, y me calumnian y saben que no es asi, ustedes que tienen las manos manchadas de crimen, de tortura, de atropello, de injusticia: ¡conviértanse! Los quiero mucho, me dan lástima, porque van por caminos de perdición (Homilía 10 de septiembre de 1978, V, p. 180).

Y para terminar este apartado, digamos que en Monseñor se hizo realidad una de las bienaventuranzas más paradójicas: la alegría en la persecución. En su formulación, y siguiendo una larga tradición de los santos, ve Monseñor que los ataques y difamaciones contra su persona lo identifican más con Jesús, y no hay alegría mayor.

¡Cristo es piedra de escándalo! Por eso a mí me hacen un inmenso honor cuando me rechazan, porque me parezco un poquito a Jesucristo que también fue piedra de escándalo (Homilía 31 de diciembre de 1978, VI, p. 88).

Las calumnias, lejos de doblegar su espíritu y empujarlo al pesimismo, lo confortaron y fortalecieron. El siguiente texto muestra, como pocos, la fe de Monseñor, su íntima relación con Cristo, en medio de la persecución.

No hay derecho para estar tristes. Un cristiano no puede ser pesimista. Un cristiano siempre debe alentar en su corazón la plenitud de la alegría. Hagan la experiencia, hermanos, yo he tratado de hacerla muchas veces y en las horas más amargas de las situaciones, cuando más amecia la calumnia y la persecución, unirme íntimamente a Cristo, el amigo, y sentir una dulzura que no la dan todas las alegrías de la tierra. La alegría de sentirse íntimo de Dios, aun cuando el hombre no lo comprenda a uno. Es la alegría más profunda que pueda haber en el corazón (Homilía 20 de mayo de 1979, VII, p. 349).

Difamación y persecuciones no fueron, pues, una sorpresa para Monseñor, sino que fueron consecuencia de su opción, y -evangélicamente- le produjeron también satisfacción y gozo. Y la razón fundamental para todo ello la comprendió Monseñor con toda lucidez: fue difarnado y perseguido porque estuvo donde tenía que estar: junto al pueblo. «El pastor tiene que estar donde está el sufrimienton (Homilía 30 de oclubre de 1977, I-II, p. 296).

\subsection{Amenazas de muerte: con el pueblo hasta el final}

De las calumnias se pasó a las amenazas de muerte con el fin de

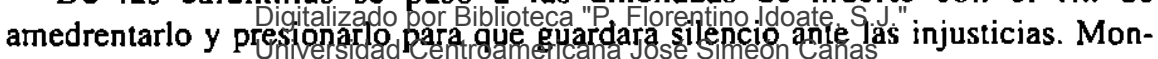
señor Romero fue frecuentemente amenazado de muerte. Su nombre encabezaba 
la lista de sentenciados a muerte, que hacían circular los escuadrones de la muerte. En esta situación, pronunció sus palabras más bellas de fidelidad a Dios $y$ de amor a su pueblo.

Lo primero que hay que decir es que Monseñor Romero siempre antepuso la seguridad del pueblo a su propia seguridad personal, la vida de los pobres a su propia vida. Un día lo dijo pública y solemnemente. En enero de 1979, como respuesta a una amenaza a muerte que Monseñor Romero hizo pública en su homilía, cl Presidente de la República le ofreció poner a su disposición los servicios de seguridad del gobierno. Monseñor Romero respondió así a tal ofrecimiento:

Muchas gracias, Señor Presidente, por escucharme. Y también quiero agradecerle el haber ofrecido proporcionarme protección si yo se la solicitaba. Se lo agradezco, pero quiero repetir aquí mi posición: que no busco yo nunca mis ventajas personales, sino que busco el bien de mis sacerdotes y de mi pueblo... Antes de mi seguridad personal, yo quisiera seguridad y tranquilidad para 108 familias y desaparecidos, para todos los que sufren. Un bienestar personal, una seguridad de ini vida no me interesa mientras mire en mi pueblo un sistema económico, social y político que tiende cada vez más a abrir esas diferencias sociales (Homilía 14 de enero de 1979, VI, pp. 121-122).

En csta cita, Monseñor Romero se dirige al presidente, General Romero. Las palabras son corteses, pero proféticas y hasta irónicas. En noviembre de 1979. vuelve a repetir la misma idea, pero en un contexto político distinto. En el poder estaba ya la junta de gobierno, en la que, en principio, Monseñor vefa buena intenciones. Por aquellos días, el nuncio le había comunicado que su vida corría peligro, y la junta de gobierno tenía gran interés en que no le sucediera nada. En este contexto hay que entender lo que dice en su Diario. Sus palabras no son ya tanto proféticas e irónicas, sino de principio.

Tambien lo comenté [la amenaza] con dos personeros del gobierno que vinieron a visitarme, y los cuales me dijeron que era conveniente denunciarlo en público, y que si quería me daban ellos garantía, hasta un vehículo blindado. Pero les dije que quería seguir corriendo los mismos riesgos de mi pueblo, y que no seria edificante una seguridad de esa clase".

En conclusión, en medio de amenzas graves e in crescendo, Monseñor Romero siempre reafirmó su compromiso de buen pastor, que no abandona a su pueblo. No hay que añadir comentarios al siguiente texto que rezuma evangelio y humanidad. Monseñor Romero promete públicamente mantener hasta el final lo que, sin duda, sabía que le costaría la vida.

9. Monseñor Oscar Arnulfo Romero. Su Diario (San Salvador, 1990) p. 323. Monseñor fue muy consciente de las amenazas contra su propia vida, y a ello hace referencia en

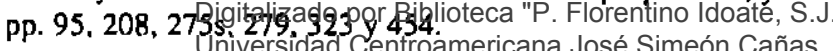


Quisiera aclarar un punto. Se ha hecho bastante eco a una noticia de amenazas de muerte a mi persona... Quiero asegurarles a ustedes, y les pido oraciones para ser fiel a esta promesa, que no abandonaré a mi pueblo, sino que correré con él todos los riesgos que mi minislerio me exige (Homilía 11 de noviembre de 1979, VII, p. 432).

A medida que se acercaba el 24 de marzo, Monseñor se refirió cada vez más a su muerte, y su palabra fue adquiriendo definitividad. Terminemos con dos lextos. Uno de ellos es el último testimonio que Monseñor Romero ofreció en sus homilias sobre las amenazas a muerte, justamente un mes antes de su asesinalo. El texto se dirige proféticamente contra los responsables de la represión al pueblo y contra quienes, en última instancia, terminarían con su vida.

Espero que este llamado de la Iglesia no endurezca aún más el corazón de los oligarcas, sino que los mueva a la conversión. Compartan lo que son y tienen. No sigan callando con la violencia a los que les estamos haciendo esta invitación, ni mucho menos, continúen matando a los que estamos tralando de lograr que haya una más justa distribución del poder y de las riquezas de nuestro país. $Y$ hablo en primera persona, porque esta semana me llegó un aviso de que estoy yo en la lista de los que van a ser eliminados la próxima semana. Pero que quede constancia de que la voz de la justicia nadie la puede matar ya (Homilía 24 de Sebrero de I980, VIII, p. 275).

Y lo mataron. Como a Jesús, no le quitaron su vida, sino que él la dio libremente. Más aún, Monseñor Romero no consideró su vida como propia, sino que pertenecía al pueblo: «mi vida no me pertenece a mí, sino a ustedes» (Homilia 21 de agosto de 1977, I-II, p. 182).

El texto lo dice todo, y lo dice con una sencillez impresionante. Pocos días antes de ser asesinado, al periodista que lo entrevistaba le dijo unas palabras, que han quedado para siempre como testamento, palabras de despedida, como las de Jesús en el evangelio de Juan.

He sido frecuentemente amenazado de muerle. Debo decirle que, como cristiano, no creo en la muerte sin resurrección. Si me malan, resucilaré en el pueblo salvadoreño. Se lo digo sin ninguna jactancia, con la más grande humildad.

Como pastor estoy obligado por mandato divino a dar la vida por quienes amo, que son todos los salvadoreños, aun por aquellos que vayan a asesinarine. Si llegaran a cumplirse las amenazas, desde ya ofrezco a Dios mi sangre por la redención y resurrección de El Salvador.

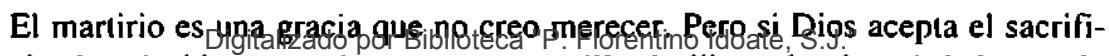
cio de mi vidaniqueidrad sangoenseacsenjibé dentibertaichay la señal de que la 
esperanza será pronto una realidad. Mi muerte, si es aceptada por Dios, sea por la liberación de mi pueblo y como un testimonio de esperanza en el futuro.

Puede usted decir, si llegasen a matarme, que perdono y bendigo a quienes lo hagan. Ojalá, sí, se convenzan que perderán su tiempo. Un obispo morirá, pero la Iglesia de Dios, que es el pueblo, no perecerá jamás ${ }^{10}$.

10. La voz de los sin voz. La palabra viva de Monseñor comero (San Salvador, 1986), p. 461 . 